Session 2215

\title{
A Team Oriented, Case-based Approach for a Transportation Engineering Course
}

\author{
Shashi S. Nambisan, Ph.D, P.E. \\ Professor of Civil Engineering \\ University of Nevada, Las Vegas \\ 4505 Maryland Parkway, Las Vegas NV 89154-4015 \\ Tel: (702) 895-1325, fax (702) 895-4401, E-mail: shashi@ce.unlv.edu
}

\begin{abstract}
Teamwork and the ability to work with contemporary and emerging technologies that facilitate collaboration are critical to the engineering profession today. Team oriented, casebased methods can be effective tools for learning. The use of well designed collaborative activities can be effective for enhancing student learning. This paper summarizes both the efforts and results in developing a team oriented, case-based approach for a junior level introductory course in Transportation Engineering. The intent of this approach is to support student acquisition of knowledge and a context sensitive use of the skills necessary for success in the profession. The approach used is based on the following beliefs:
\end{abstract}

1. Realistic learning activities presented as cases promote learning.

2. Collaboration is vital for learning and for success in the profession.

The paper includes examples of the strategies used to facilitate learning, instruments used to assess the effectiveness of the approach, and results from the experiences. In summary, some students are reluctant to participate in "team" efforts. They indicate that they enjoy the casebased approach. In general, the team oriented, cased-based approach helps students make the connection from acquiring / processing information to developing knowledge and applying the same.

\section{Introduction}

A junior level introductory Transportation Engineering course is typical in the core undergraduate curriculum in Civil Engineering. CEG 362: Transportation Engineering is a required 3-credit course in the undergraduate curriculum in Civil Engineering at the University of Nevada, Las Vegas. Such a course would include topics in the life cycle of a transportation project (policy, planning, design, construction, operations, maintenance and rehabilitation) in the context of several modes (highway, transit, air, rail, water, etc.). Course objectives include linking concepts learned in this course to those from other courses and vice-versa, i.e., integration across the curriculum. In this process, students "learn" the interactions and tradeoffs between policy (technology considerations, financing issues, social and environmental 
concerns), planning (estimating / modeling traffic volumes, traffic mix, axle loads, etc.), design (how many lanes, width of lanes, type of pavement structure, thickness of pavement, etc.), construction (economics, benefits, feasibility etc.), operations (desired levels of service, signal timing, lane configurations, etc.), and maintenance and rehabilitation (pavement and other rightof-way elements, frequency and magnitude of activities, etc).

The author has taught this course almost every semester for the last 8 years. Early on, the author adopted the traditional approach of lecturing, assignments, and examinations to "teach" this course in the undergraduate Civil Engineering curriculum. While these led to some amount of "success" (i.e., learning by students), they appeared to fall short of the author's goals of fostering "learning" and "application of knowledge." Thus, the author began evaluating alternative approaches to help students "learn" and "retain" the information, and convert the same to appropriate "knowledge."

\section{Literature Review}

The ability to work effectively on teams, and the ability to work with contemporary and emerging technologies are cited along with the need for good communication skills and time management as the most desirable traits that employers seek in new graduates. These are also skills that are invaluable for graduate studies as well. Further, the Accreditation Board for Engineering and Technology (ABET) identifies these among the criteria in Engineering Criteria $2000^{1}$, Fortenberry ${ }^{2}, \mathrm{Koehn}^{3,4}$, and $\mathrm{UNLV}^{5}$. Examples in the literature that address collaborative learning include the following: Johnson, Johnson and Smith ${ }^{6}$, and Kaufman, Felder and Fuller ${ }^{7}$.

Historically Civil Engineering programs have used case studies to introduce and illustrate key concepts and their applications. Pedagogical studies have shown that a topical use of case studies in engineering education in general, and in Civil Engineering education in particular, provides educational benefits to students by helping them better understand complex concepts

and their relevance to an engineering project's life cycle (Chinowsky and Robinson ${ }^{8}$, Fitzgerald ${ }^{9}$, Kolar and Sabatini ${ }^{10,11}$, Mahendran ${ }^{12}$, Smith and $\left.\operatorname{Kardos}^{13}\right)$.

\section{Approach}

Over the last few years, the author has experimented with various approaches with the following goals: help students learn basic principles; retain the information presented in the course; develop skills to utilize the information for analysis, design, and evaluation purposes; and to convert the information to appropriate knowledge. Examples of such efforts include collaborative learning, case based exercises, utilization of web-based tools, and team projects. In-class as well as out-of-the-classroom cooperative learning exercises and collaborative learning efforts such as team projects, and some limited web-based tools have been used in to support the case-based learning strategy. The use of cases and team efforts are the subject of this paper. 


\section{Case-Based Learning}

The author has used a case based approach, wherein one or two example cases are utilized to link the phases in the life cycle of a typical transportation system. One specific example is the design of a roadway section for some future year. At the outset, a specific link on a "future" highway network is selected for the case-based learning experience. An ultimate objective for the semester is to design the link. Information necessary to design this link include the following:

- What are the engineering, economic, environmental, and societal considerations?

- What are the engineering features / elements that need to be designed?

- What are the factors that affect the design?

- How do the design elements influence each other?

- What are other non-technical and technical issues that need to be addressed?

During the semester, concepts pertaining to the aforementioned considerations are introduced during the class "lectures." In addition, to connect the concepts with real life applications, the instructor and the students present and discuss examples from transportation systems - these may be local, national, or international.

Specifically, a street segment proximate the university campus is selected as the link to be designed. The course is broken up into modules that cover the following broad topical areas: planning, design, operations. Planning includes the following:

- identification of the design year and the functional life of the facility

- $\quad$ persons expected to traverse the link in (travel demand forecasting),

- conversion of demand from person trips to the number of vehicles and types of vehicles

- economics, environmental and social considerations

The Design module includes the following topics:

- determination of the right of way requirements, number of lanes, lane and shoulder widths

- determination of the facility's alignment - horizontal and vertical curves

- determination of pavement type and design of the pavement cross-section

The Operations module includes the following topics:

- determination of capacity and relationships to demand

- identification of traffic control strategies

- determination of level of service

Class discussions include information related to the local street chosen for the case study. The same link is used in examples and class discussions throughout the semester. However, homework assignments and exams do NOT make use of this "case at hand." - instead, they are based on problems or questions from various chapters in the textbook in which chapters are independent of one another. This strategy offers advantages and disadvantages. The main disadvantage is that the "context (setting)" of the homework assignments is not related to the class discussions (but, they are based on the materials presented in the text book). However, this 
disadvantage may also be looked upon as an advantage where the students are being required to apply their knowledge in new settings, which help diversify their exposure.

Familiarity with the "case" helps students relate concepts to practice, obtain a feel for the "order of magnitude" of the problem, synthesize the information, and apply it to other situations that may or may not be similar in nature (e.g., larger or smaller facilities). One important point to note is that familiarity with the case helps instill confidence among the students and helps alleviate the discomfort often associated with being in "unfamiliar territory."

The case-based approach also helps students make a connection between the various modules of the class. More importantly these modules reflect stages in the life cycle of transportation systems. Thus, the students are able to make a real connection between theory and practice.

\section{Team-Oriented Learning}

Team oriented learning is adopted in two ways. The first is through formal teams that are formed at the beginning of the semester with each team working together for the rest of the semester on a term project. The second team oriented learning strategy is the use of informal teams that last only for the duration of each class period. These are next discussed in further detail.

\section{Teams for the Term Project}

The topic for the term project may be the same for the entire class (in some semesters) or individual teams are permitted to develop a topic for approval by the instructor. Often, the topics are selected by the instructor in collaboration with one of the local transportation agencies. They generally are based on the local transportation system. Topics for the term project are such that students are required to apply theoretical concepts. These concepts may not all be acquired from class discussions or the text books. To successfully complete the project students will have to acquire some knowledge required from other reference materials or transportation practitioners.

Teams for the term project generally consist of two or three individuals per team. Strategies used for the selection of teams include self selection by students, and assignment of teams by the instructor. Each team is to work jointly on a term project for the entire semester. The project requires several deliverables during the semester. These include the following:

- a written proposal

- two written progress reports

- a written final report

- an oral presentation

Teams are encouraged to submit draft versions of the documents for comments from the instructor. If these drafts are submitted at least one week prior to the due date of the final report, the instructor provides comments on these documents so as to enable to teams to incorporate these comments in their "final" submissions. Each team's efforts must be summarized in one "deliverable" - and not individually for each team member. For the final oral presentation, the

\footnotetext{
"Proceedings of the 2002 American Society for Engineering Education Annual Conference \& Exposition Copyright
} (C) 2002, American Society for Engineering Education" 
instructor reserves the right to ask any team member to make any portion of the presentation (i.e, each team member must be prepared to make the entire presentation).

Each team's written work is evaluated and a grade is assigned to the entire team. However, this grade is distributed among the team members based on their respective contributions to the project. Individual contributions to the project are determined primarily based on self assessments by team members. The self assessments are reported with each interim progress report. This assessment requires each team member to document his / her contribution to the team's product. Further, each student is asked to assign a score to each member on the team such that the total score adds up to 100 points. Individual team member assessments are tabulated and averaged for each student to obtain the student's contribution to the team. In case of significant differences between team member evaluations, the instructor meets with the team as a whole to try to reconcile the differences. Each student's score is computed as the product of the team's total score and the student's score for contribution to the team.

\section{Teams for Individual Class Sessions}

Teams for individual class sessions are informal. They are created "on the fly" on an as needed basis. They are used no more than two or three times per class period ( 75 minutes duration). Students are asked to form teams of two or three individuals with others seated close to them. This practice often leads to teams compositions remaining fairly unchanged during the semester. The instructor could require students not to sit next to the same individual in successive classes so as to change this phenomenon.

After a new concept or topic has been presented by the instructor and discussed in the class, the instructor presents the class with a question or questions. Students are asked to form such teams to respond to these questions and they are provided about 1 to 5 minutes for the same. The instructor's policy is that any student may be called upon to present the team's response. This is to encourage all students to participate in developing the response(s). Even if an individual did not have a response on his/her own, s/he would be able to provide the "team's" response. This not only helps students to learn from one another, but also to not be afraid of not having a response.

The instructor does not grade students based on the team exercises conducted during class sessions.

\section{Assessment}

The effectiveness of the aforementioned approaches has been assessed informally over the last four years. Assessment tools used include periodic surveys such as mid-semester and endof-semester course evaluation surveys, surveys to assess learning from team / collaborative / cooperative learning efforts (both for the individual and for the team), and oral presentations. Some of these instruments are based on peer evaluations, and they all are shared with the class. More recently, over the last year, an "entry quiz" administered on the first day of the semester,

\footnotetext{
"Proceedings of the 2002 American Society for Engineering Education Annual Conference \& Exposition Copyright
} (C) 2002, American Society for Engineering Education" 
and an identical "exit quiz" administered on the last day of the semester have also been used to assess the learning, information retention, and knowledge development that occurred during the semester. All of these tools are "paper-based." Collecting the information is time consuming and the information is difficult to aggregate, thus making it challenging to provide timely and substantive feedback to students. As an illustration of the assessment of student performance, student learning, and experiences in team oriented activities, some results from surveys conducted during the Fall 2001 semester (the most recently completed term where the strategies were used) are presented next.

\section{Results}

The mid-semester and end-of-semester assessment of student learning, participation in team efforts, and the effectiveness of team activities consists of a two part survey. Each survey is no more than one page long and consists of several statements / questions to which each student needs to provide a confidential response on a Likert scale. The first part of the survey is intended to assess "individual" performance, experience, and contributions to the team's activities. The second part of the survey is intended to assess "team" performance and effectiveness.

A summary of the individual performance assessment tool, and the results obtained from a survey using this tool during the Fall 2001 semester is presented in Table 1.

\section{Table 1: Summary of Survey of Personal Evaluation of Working on Teams (14 students in the class)}

\begin{tabular}{|c|l|c|c|c|}
\hline No. & \multicolumn{1}{|c|}{ Question } & Min & Avg & Max \\
\hline 1 & I felt comfortable working with this team & 3 & 3.71 & 4 \\
\hline 2 & I was an active participant in my team & 3 & 3.71 & 4 \\
\hline 3 & I listened to everyone on my team & 3 & 3.79 & 4 \\
\hline 4 & I encouraged and praised others on my team & 3 & 3.50 & 4 \\
\hline 5 & I explained/helped someone who didn't understand & 2 & 3.43 & 4 \\
\hline 6 & I asked for an explanation or help when I didn't understand & 1 & 3.57 & 4 \\
\hline 7 & I felt encouraged by people in my team & 2 & 3.57 & 4 \\
\hline \multirow{2}{*}{8} & $\begin{array}{l}\text { My role was } \\
\text { role I felt comfortable with this }\end{array}$ & 3 & 3.77 & 4 \\
\hline 9 & I found this group activity to be a worthwhile experience & 3 & 3.50 & 4 \\
\hline 10 & I enjoy working with my classmates on teams & 3 & 3.71 & 4 \\
\hline \multirow{2}{*}{} & Minimum & 1.00 & & \\
\cline { 2 - 6 } & Average & & 3.62 & \\
\cline { 2 - 5 } & Maximum & & 4.00 \\
\cline { 2 - 5 }
\end{tabular}

Note: Survey responses were on a scale of 0 to 4 . A response of 0 indicates "No, not at all" and 4 indicates "Yes, a lot."

"Proceedings of the 2002 American Society for Engineering Education Annual Conference \& Exposition Copyright (C) 2002, American Society for Engineering Education" 
As can be seen from the results presented in Table 1, students in the class as a whole were very positive of their personal learning, participation in team efforts. The lowest score (3.43/4.00) corresponded with item number 5 - explaining or helping others understand. One of the highest scores $(3.77 / 4.00)$ was for item number 8 - the individual's comfort with his/her role on the team. Further, students, in general, indicate strongly that they enjoy working with their team mates (3.71/4.00), and that they were comfortable working with their team mates $(3.71 / 4.00)$, participating on team activities $(3.71 / 4.00)$, and listening to their team mates $(3.79 / 4.00)$.

A summary of the "team" assessment tool, and the results obtained from a survey using this tool during the Fall 2001 semester is presented in Table 2. This survey was a companion to the survey results shown in Table 1.

Table 2: Summary of Survey of Team Performance Evaluation (14 students in the class)

\begin{tabular}{|c|l|c|c|c|}
\hline No. & \multicolumn{1}{|c|}{ Question } & Min & Avg & Max \\
\hline 1 & Effective Use of Time & 3 & 4.31 & 5 \\
\hline 2 & Development of ideas & 3 & 4.69 & 5 \\
\hline 3 & Ability to decide Issues & 4 & 4.62 & 5 \\
\hline 4 & Overall Productivity & 3 & 4.46 & 5 \\
\hline \multirow{2}{*}{} & Minimum & 3 & & \\
\cline { 2 - 5 } & Average & & 4.52 & \\
\cline { 2 - 5 } & Maximum & & & 5 \\
\cline { 2 - 5 }
\end{tabular}

Note: Survey responses were on a scale of 1 to 5 with 1 being the worst (lowest productivity or least desirable) and 5 being the best (highest productivity or most desirable).

As can be seen from Table 2, students in the class as a whole were very positive of the performance and effectiveness of their teams. The lowest score (4.31) was for "effectiveness use of time and the highest score (4.69) was development of ideas.

The Team Performance survey also required each student to provide confidential quantitative scores for each member of the team to reflect each person's contributions to the team's activities. In general, there was consistency among team members evaluation of each other's contributions to the team's activities. Discrepancies in this regard correlated with poorer "scores" on the survey regarding effectiveness of teams and also on "individual performance" surveys.

Both the Personal Evaluation survey and the team performance survey also asked for qualitative comments and feedback. Comments provided in this regard typically focused on 
issues related to coordination of team activities and team member schedules. Occasionally, they also reflected complaints about "unbalanced" work loads among team members regarding contributions to the team's activities. Such complaints also correlate with discrepancies regarding scores given to team members by each other.

Another assessment tool used was a mid-semester confidential survey. This survey addressed all aspects of the course, and not just team related activities. However, two of the items (questions) on the survey related to student learning in the course. They are summarized in Table 3. The responses indicate there is strong support for the notion that students believe that they were learning in the class, and applying the concepts learned.

Table 3: Summary of Survey Relating to Student Learning (14 students in the class)

\begin{tabular}{|c|l|c|c|c|}
\hline No. & \multicolumn{1}{|c|}{ Question } & Min & Avg & Max \\
\hline 4 & I have had an opportunity to learn in this class & 2 & 4.17 & 5 \\
\hline 5 & I have learnt concepts and their applications in the class. & 3 & 4.17 & 5 \\
\hline
\end{tabular}

Note: The responses were on a scale of 1 to 5 as follows: $1=$ Strongly Disagree, $2=$ Disagree, 3 $=$ Neutral, $4=$ Agree, and $5=$ Strongly Agree.

The mid-semester survey, as well as an end of the semester survey, also asked students to provide qualitative comments and feedback. The most common comments in these portions of the surveys included the appreciation of the use of local and regional examples (case-based approach!), the magnitude of work required for the class (the general feeling is that this course is extremely demanding and has a heavy work load), the team activities while being difficult to coordinate were enjoyable and helped the learning and understanding processes.

\section{Summary and Conclusions}

The author's experience over the last few years has shown that using a case-based approach, combined with team learning strategies, is very effective in helping students move from rote learning to understanding the course materials. This approach also helps students better transform information to usable knowledge, and to apply the same in a context sensitive manner.

Students indicate that they enjoy the case-based approach. In mid-semester and end-ofsemester evaluations, student state strongly that the use of cases, especially examples from the region, help them understand concepts and apply the same. Most students are initially reluctant to participate in "team" efforts. The primary complaints against the team efforts are that students find it difficult to coordinate their schedules outside of class hours to work on the project. Other complaints include difficulties in working with certain individuals, some individuals not carrying their fair share of the team's work load. However, many students indicate that they enjoyed the team work experience, and that they look forward to similar opportunities in other courses. It is felt that a principal reason for this is the fact that "self selection" of team mates helped constitute a majority of each team's members. One specific concern that needs to be addressed is that a

\footnotetext{
"Proceedings of the 2002 American Society for Engineering Education Annual Conference \& Exposition Copyright (C) 2002, American Society for Engineering Education"
} 
large proportion of the students are non-traditional, and they have needs and constraints that differ greatly from the "traditional" students. The primary obstacle faced by such students relates to scheduling team efforts outside of class.

One of the biggest problems encountered in developing and implementing many of the innovative approaches in CEG 362 has been the lack of appropriate supporting materials. Textbooks existing in the market, as well as some of those currently being developed by leading publishers, treat each of these phases in a disjointed manner. In spite of not having an appropriate textbook or other reference materials to support such efforts, course evaluations have shown that these approaches have been well received by the students and that they have been effective in meeting the stated goals.

The use of the team oriented case-based approach has NOT resulted in any significant reduction of the course content. The syllabus and topics "uncovered" in the course remain essentially unchanged, but for minor variations from semester to semester. The additional burden related to record keeping is acknowledged. But, the availability of a portion of a Graduate Assistant's time during each semester (approximately 10 hours per week) has helped in this regard. It is to be noted that the Graduate Assistant's time also includes time spent on grading assignments, and helping with other administrative and record keeping issues for the course. Such support has been available even before the new approach was adopted for the course.

The author's experience over the last few years has shown that using a case based approach, combined with "team" learning strategies, is very effective in enhancing students learning in a junior level introductory Transportation Engineering course. Formal course evaluation tools and anecdotal evidence based on student feed back have shown that these approaches are well received by the students and that they have been effective in helping students to better "learn" and "retain" the information, and convert the same to appropriate "knowledge." Some students report difficulties in working on team efforts primarily because of schedule conflicts. In general, the team oriented, cased-based approach helps students make the connection from acquiring / processing information to developing knowledge and applying the same.

\section{Acknowledgments}

The author gratefully acknowledges the assistance provided by the Graduate Assistants who helped with some of the administrative and record keeping issues that are so critical for the course. The financial support provided to these assistants by the Department of Civil and Environmental Engineering, the College of Engineering, and the Graduate College at UNLV is greatly appreciated. Further, three anonymous referees are thanked for their comments and recommendations which have helped improve the quality of the manuscript. The author also thanks Professor Walter Vodrazka, his colleague at UNLV, for comments that helped improve the readability of the manuscript.

\footnotetext{
"Proceedings of the 2002 American Society for Engineering Education Annual Conference \& Exposition Copyright
} (C) 2002, American Society for Engineering Education" 


\section{References}

1. Accreditation Board for Engineering and Technology (1999). "Criteria for Accrediting Engineering Programs: Effective for Evaluations During the 2000-2001 Accreditation Cycle," Baltimore, MD. November. URL: http://www.abet.org/images/eac_criteria_a.pdf

2. Fortenberry, N.L. (1994). 'Troubles with Undergraduate Education," What's Due, Vol. 2, No. 6, National Science Foundation, Division of Undergraduate Education, Arlington, VA, DUE Staff Report NSF940621.

3. Koehn, E. (1995). "Practitioner and Student Recommendations for an Engineering Curriculum," Journal of Engineering Education, July pp. 241-248.

4. Koehn, E. (1999). "Preparing Students for Engineering Design \& Practice," Journal of Engineering Education, April. pp. 163-167.

5. UNLV (1997). “A Survey of Employers of UNLV's Civil Engineering Alumni.” Unpublished Document. Department of Civil and Environmental Engineering, University of Nevada, Las Vegas, NV.

6. Johnson, D. W., R. T. Johnson, and K. A. Smith (1998). Active Learning: Cooperation in the College Classroom, Interaction Book Co., Edina, MN.

7. Kaufman, D. B., R. M. Felder, and H. Fuller (2000). “Accounting for Individual Effort in Cooperative Learning Teams," Journal of Engineering Education, April, pp. 133-140.

8. Chinowsky, P. S. and J. Robinson (1997). "Enhancing Civil Engineering Education Through Case Studies," Journal of Engineering Education, January. pp. 45-49.

9. Fitzgerald, N. (1995) “Teaching With Cases," ASEE Prism, March. pp. 16-20.

10. Kolar, R. L. and D. A. Sabatini (1996). "Coupling Team Learning and Computer Technology in Project-Driven Undergraduate Engineering Education," Proceedings, FIE `96 (Frontiers in Education), Iskander et al, eds., IEEE (CD-ROM).

11. Kolar, R.L. and D. A. Sabatini (1997), "Changing from a Lecture-Based Format to a Team Learning/Project Driven Format: Lessons Learned,"Proceedings of the 1998 ASEE Annual Conference, ASEE, Session \#1675, CD-ROM.

12. Mahendran, M. (1995). "Project-Based Civil Engineering Courses," Journal of Engineering Education, January. pp. 1-5.

13. Smith, C. and G. Cardos. (1990). "Spice Your Class With a Slice of Life," Proceedings of the 1990 ASEE Annual Conference, ASEE, Washington, D.C., pp. 482-484.

\section{Biographical Information}

Shashi Sathisan Nambisan is a Professor of Civil Engineering and the Director of the Transportation Research Center at the Howard Hughes College of Engineering, University of Nevada, Las Vegas. His educational and research interests focus on transportation systems and information technology.

"Proceedings of the 2002 American Society for Engineering Education Annual Conference \& Exposition Copyright (C) 2002, American Society for Engineering Education" 